\title{
Coal pricing mechanism of some countries in the world and lessons learned for Vietnam national Coal - Mineral industries holding corporation limited
}

\author{
Tan Cong Nguyen 1, ${ }^{,}$, Ha Thu Thi Luu 2, Bich Thi Dong ${ }^{2}$
}

1 Vinacomin Industry investment consulting joint stock company, Hanoi, Vietnam

2 Faculty of Economics and Business Administration, Hanoi University of Mining and Geology, Vietnam

\begin{tabular}{|c|c|}
\hline ARTICLE INFO & ABSTRACT \\
\hline $\begin{array}{l}\text { Article history: } \\
\text { Received 10th Aug. } 2020 \\
\text { Revised 03rd Sept. } 2020 \\
\text { Accepted 31 }\end{array}$ & $\begin{array}{l}\text { As one of the two largest coal production and trading units in Vietnam, } \\
\text { Vietnam National Coal - Mineral Industries Holding Corporation Limited } \\
\text { (Vinacomin) is still operating both under the planning mechanism and } \\
\text { the market mechanism. Additionally, in recent years, the group's coal }\end{array}$ \\
\hline $\begin{array}{l}\text { Keywords: } \\
\text { Coal mining, } \\
\text { Coal pricing mechanism, } \\
\text { Market economy, } \\
\text { Vinacomin. }\end{array}$ & $\begin{array}{l}\text { price is also being built under these mechanisms. In the context of } \\
\text { increasingly deep integration, fluctuating coal price and market, the } \\
\text { competition of imported coal is getting more and more fierce, while coal } \\
\text { mining conditions are increasingly difficult, the coal production and } \\
\text { trading still have many shortcomings, so it is necessary to have a coal } \\
\text { price determination mechanism accordance with the actual conditions of } \\
\text { the Vietnamese coal market. Therefore, in order to determine the coal } \\
\text { price scientifically and in association with practice, the reference to the } \\
\text { coal pricing mechanism in some countries around the world to draw } \\
\text { lessons for Vinacomin plays an important role. The content of this article } \\
\text { mentions the coal pricing mechanism in some countries with a large } \\
\text { amount of coal mining and consumption such as China, Australia, Russia, } \\
\text { Indonesia,... thereby giving a comprehensive view of the coal price } \\
\text { management, operation and construction mechanism of some coal } \\
\text { markets in the world and as a reference basis for Vinacomin. }\end{array}$ \\
\hline
\end{tabular}

Copyright (c) 2020 Hanoi University of Mining and Geology. All rights reserved.

${ }^{*}$ Corresponding author

E-mail: tanimcc@yahoo.com

DOI: 10.46326/ JMES.KTQT2020.09 


\title{
Tạp chí Khoa học Kỹ thuật Mỏ - Địa chất
}

Trang điện tử: http://tapchi.humg.edu.vn

\section{Cơ chế định giá than của một số quốc gia trên thế giới và bài học kinh nghiệm cho Tập đoàn Công nghiệp Than - Khoáng sản Việt Nam}

\author{
Nguyễn Công Tân 1,* Lưu Thị Thu Hà ${ }^{2}$, Đồng Thị Bích ${ }^{2}$ \\ 1 Công ty cổ phần Tư vấn đầu tư mỏ và công nghiệp -Vinacomin, Hà Nội, Việt Nam \\ 2 Khoa Kinh tế và Quản trị kinh doanh, Trường Đại học Mỏ - Địa chất, Việt Nam
}

\begin{tabular}{|c|c|}
\hline THÔNG TIN BÀI BÁO & TÓM TÁT \\
\hline $\begin{array}{l}\text { Quá trình: } \\
\text { Nhận bài 10/ 8/ } 2020 \\
\text { Sứa xong 3/9/2020 } \\
\text { Chấp nhận đăng 31/ 10/ } 2020 \\
\text { Tù khóa: } \\
\text { Cơ chế định giá than, } \\
\text { Khai thác than, } \\
\text { Kinh tế thị trường, } \\
\text { Tập đoàn TKV. }\end{array}$ & 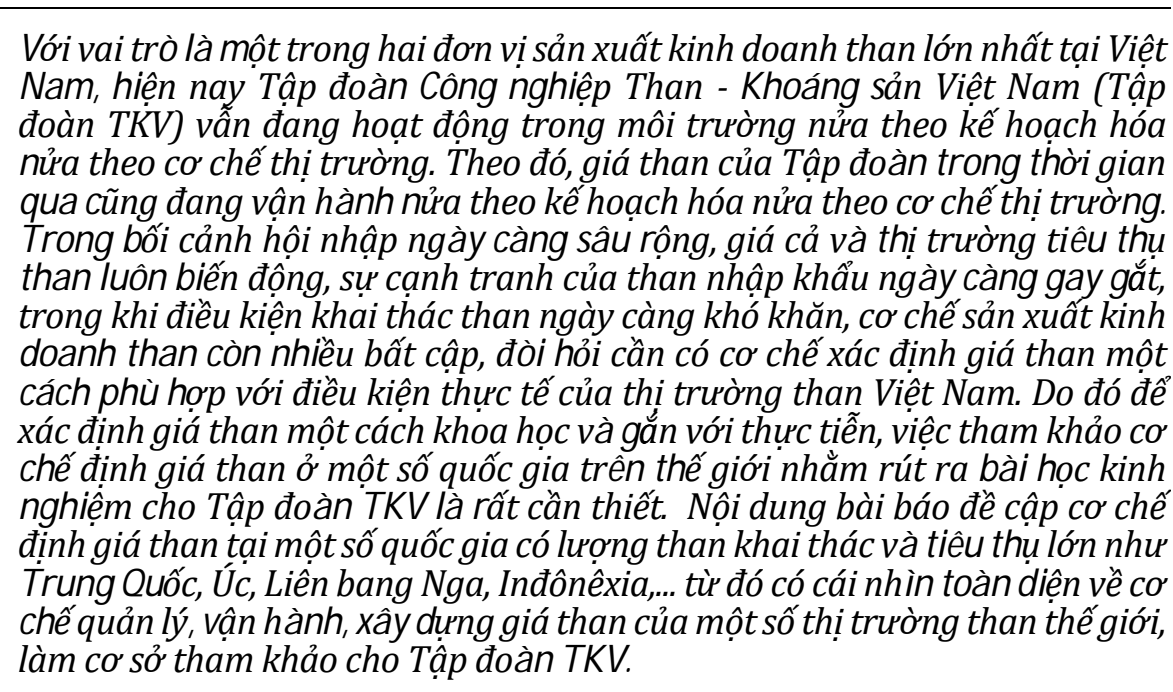 \\
\hline
\end{tabular}

(c) 2020 Trường Đại học Mỏ - Địa chất. Tất cả các quyền được bảo đảm.

\section{Mở đầu}

Từ khi nền kinh tế chuyển sang hoạt động theo cơ chế thị trường, về nguyên tắc giá than không thuộc diện Nhà nước quản lý mà được hình thành trên cơ sở thỏa thuận giữa người sản xuất và

*Tác giả liên hệ

E - mail: tanimcc@yahoo.com

DOI: 10.46326/ JMES.KTQT2020.09 người sử dụng than theo nguyên tắc thị trường "thuận mua, vừa bán".

Tuy nhiên, trên thực tế, do nền kinh tế Việt Nam là nền kinh tế thị trường định hướng xã hội chủ nghĩa có sự quản lý của Nhà nước hội nhập ngày càng sâu rộng, nhưng chưa thiết lập được thể chế quản lý, vận hành đồng bộ và phù hợp, nên thời gian vừa qua các doanh nhiệp thuộc ngành than vẫn còn gặp nhiều khó khăn, vướng mắc trong cơ chế vận hành của thị trường than, trong đó có cơ chế về giá than, nhất là giá than cho sản 
xuất điện liên quan đến an ninh năng lượng quốc gia.

Với vai trò là một trong hai đơn vị sản xuất kinh doanh than lớn nhất tại Việt Nam, hiện nay Tập đoàn Công nghiệp Than - Khoáng sản Việt Nam (Tập đoàn TKV) vẫn đang hoạt động trong môi trường nửa theo kế hoạch hóa (chiến lược, quy hoạch, kế hoạch hàng năm) nửa theo cơ chế thị trường. Theo đó, giá than của Tập đoàn trong thời gian qua cũng đang vận hành nửa theo kế hoạch hóa nửa theo cơ chế thị trường. Trong bối cảnh hội nhập ngày càng sâu rộng, giá cả và thị trường tiêu thụ than luôn biến động, sự cạnh tranh của than nhập khẩu ngày càng gay gắt, trong khi điều kiện khai thác than ngày càng khó khăn cùng với chính sách thuế, phí tăng cao làm cho giá thành than tăng cao và cơ chế sản xuất kinh doanh than còn nhiều bất cập, đòi hỏi cần có cơ chế xác định giá than một cách phù hợp với điều kiện thực tế của thị trường than Việt Nam. Do đó để xác định giá than một cách khoa học và gắn với thực tiễn, việc tham khảo cơ chế định giáthan ở một số quốc gia trên thế giới nhằm rút ra bài học kinh nghiệm cho Tập đoàn TKV là rất cần thiết. Nội dung bài báo đề cập cơ chế định giá than tại một số quốc gia có lượng than khai thác và tiêu thụ lớn như Trung Quốc, Úc, Liên bang Nga, Inđônêxia,... từ đó có cái nhìn toàn diện về cơ chế quản lý, vận hành, xây dựng giá than của một số thị trường than thế giới, làm cơ sở tham khảo cho Tập đoàn TKV trong việc lập văn bản kê khai giá theo quy định với cơ quan nhà nước có thẩm quyền xem xét, thẩm định, cũng như làm cơ sở hiệp thương giá và đàm phán hợp đồng mua bán than giữa người sản xuất và người sử dụng than.

\section{Chi phí làm cơ sở xác định giá than của một số quốc gia trên thế giới}

Định giá than nhiệt ở một số quốc gia trên thế giới được coi là tương đối đơn giản vì than được sử dụng cho quá trình đốt cháy có giá trị từ nhiệt lượng ròng của than, với một số tác dụng phụ được tạo ra do lượng chất ô nhiễm như lưu huỳnh, nitơ,... và các hiệu ứng bất lợi của tro như natri, lưu huỳnh, xỉ tro,... Ngoài các khoản phụ phí tuỳ theo quốc gia, chi phí than giao cho khách hàng, không phân biệt các quốc gia, thường bao gồm các khoản chi phí sau:

- Chi phí đầu tư khai thác, sàng tuyển, chế biến: gồm chi phí sản xuất (chi phí nhân công, vật liệu, nhiên liệu, động lực, khấu hao), thuế tài nguyên và chi phí vốn;

- Chi phí vận chuyển: vận tải đường sắt, vận tải đường biển, vận tải đường bộ,...;

- Chi phí cảng (nếu có);

- Lợi nhuận biên;

- Thuế và phí.

Phụ phí theo quốc gia cụ thể phụ thuộc vào đặc tính của than, than trong nước hoặc nhập khẩu, được tiêu thụ ở các quốc gia tương ứng. Ví dụ, do đặc thù của quá trình hình thành, than ở Mỹ, Canada và châu Âu, có hàm lượng lưu huỳnh cao, nhưng tương đối ít nitơ. Ngược lại, than ở Ấn Độ có độ tro rất cao và có đặc tính rất khó làm sạch (để giảm tro). Than Mỹ, Canada và châu Âu có độ tro tương đối thấp. Than Mỹ và châu Âu dễ dàng làm sạch, còn hầu hết than Canada không được như vậy. Do đó, hầu như mỗi quốc gia đều có cấu trúc giá riêng. Giá có ít nhất hai thành phần chi phí: thông số chất lượng than như đã nói ở trên và thông số thị trường phụ thuộc rất lớn vào nguồn gốc (nơi sản xuất) của than, môi trường và quy luật cung cầu, tương ứng (Nguyễn Công Tân, 2020).

\section{Cơ chế định giá than của một số quốc gia trên thế giới}

\subsection{Trung Quốc}

Tại Trung Quốc, giá than được thiết lập kể từ năm 1993 và mức giá là khác nhau tùy thuộc vào việc sử dụng than. Trước năm 2004, có hệ thống hai giá than, giá than sử dụng cho các đơn vị ngoài điện, được gọi là than thị trường, được xác định bởi thị trường; trong khi giá than sử dụng cho điện, còn gọi là than điện, dựa trên cơ sở giá hướng dẫn được thiết lập bởi Ửy ban cải cách và phát triển quốc gia (NDRC), thường ở mức giá thấp hơn giá thị trường tại cùng thời điểm. Các nhà sản xuất than được yều cầu bán cho các nhà sản xuất điện lớn với giá than được kiểm soát. Tuy nhiên, do sản lượng than được sử dụng cho điện ngày càng tăng và giá than cũng tăng lên trong khi giá điện vẫn cố định, các nhà sản xuất điện ngày càng khó mua than và trang trải chi phí sản xuất.

Năm 2004, NDRC đã bãi bỏ giá hướng dẫn đối với than cho sản xuất điện và thiết lập các mức giá cho các cuộc đàm phán giữa các nhà sản xuất than và các nhà máy điện. NDRC mở rộng miền/ khung 
giá than vào năm 2005. Năm 2006, NDRC đã loại bỏ hoàn toàn các mức giá than này.

Với mức giá điện còn được kiểm soát và không thay đổi, nhiều nhà máy phát điện đã không thể chịu được việc tăng chi phí nhiên liệu liên tục và phải chịu thua lỗ lớn. Vào tháng 5/2005 NDRC đã đề xuất một cơ chế giá điện - than "cùng chuyển động", qua đó tăng giá điện nếu giá than tăng từ $5 \%$ trở lên trong không dưới 6 tháng và cho phép các nhà sản xuất điện chuyển tới $70 \%$ chi phí nhiên liệu tăng lên cho các công ty chuyển tải điện, và các công ty chuyển tải điện sẽ chuyển chi phí này cho người tiêu dùng. Tuy nhiên, vì lo ngại lạm phát, chính sách "cùng chuyển động" đã không được thực hiện ngay cả khi các điều kiện được đáp ứng và giá điện vẫn tiếp tục không thay đổi trong khi giá than tăng. Điều này đã gây áp lực lớn hơn cho các nhà máy phát điện và dẫn đến các nỗ lực vận động hành lang cho các nhà máy điện để nhận được mức giá điện cao hơn.

Vào tháng 12 năm 2012, Hội đồng Nhà nước tuyên bố bãi bỏ hệ thống giá than hai giá. Giá than sử dụng cho điện cũng được xác định bởi thị trường giống như giá than sử dụng cho các hộ tiêu thụ ngoài điện. Hội đồng Nhà nước điều chỉnh lại cơ chế giá điện - than "cùng chuyển động". Theo cơ chế sửa đổi, giá điện sẽ được điều chỉnh nếu biến động giá than vượt quá $5 \%$ trở lên trong 12 tháng và các nhà máy điện được phép chuyển tới 90\% chi phí nhiên liệu tăng lên cho các công ty chuyển tải điện thay vì $70 \%$ như ngưỡng trước đó (ZhongXiang Zhang and Ma Yinchu, 2018).

Để thực hiện cơ chế "cùng chuyển động" theo cách cởi mờ và minh bạch hơn, vào tháng 12/ 2015, NDRC đã quy định các chi tiết vận hành cơ chế này. Kể từ đầu năm 2016, theo chu kỳ một năm, giá điện sẽ được điều chỉnh nếu giá than cho điện tăng trong phạm vi $30 \div 150$ nhân dân tệ (NDT) so với giá tham chiếu trung bình năm 2014 đối với than cho điện. Giá than càng biến động, hệ số "cùng chuyển động" càng ít. Khi giá than tăng dưới mức 30 NDT mỗi tấn, các nhà máy điện phải chấp nhận tất cả các chi phí nhiên liệu tăng lên, còn khi giá than tăng vượt mức 150 NDT mỗi tấn, cơ chế "cùng chuyển động" cũng không được áp dụng.

Cần chỉ rõ rằng cơ chế "cùng chuyển động" này không phải là cơ chế kích hoạt tự động, nghĩa là nó có thể không được thực hiện ngay cả khi các điều kiện được đáp ứng. Trên thực tế, mức tăng trung bình giá than trong cả năm 2017 đã giảm vào đầu năm 2018 trong phạm vi nói trên, nhưng cơ chế "cùng chuyển động" đã không được thực hiện. Điều này có thể là do việc thực hiện cơ chế "cùng chuyển động” bằng cách tăng giá điện sẽ làm tổn hại lợi ích của những người sử dụng điện hạ nguồn trong môi trường kinh tế kém thuận lợi trên toàn thế giới lúc bấy giờ.

\subsection{Indonexia}

Indonexia, nhà xuất khẩu than lớn ở châu Á sau Ấn Độ và Trung Quốc, đã đưa ra một cơ chế định giá chuẩn cho than, bao gồm cả than nhiệt kể từ tháng 2/2010 cho các nguồn cung trong nước cũng như thị trường xuất khẩu. Việc định giá là minh bạch và được thực hiện bằng cách sử dụng bốn chỉ số than được quốc tế chấp nhận để tạo ra giá than tham chiếu hàng tháng cho khoảng 62 loại than, bao gồm 8 loại chất lượng chuẩn (Rachit Tiwari, 2015). Tổng cục Khoáng sản và Than (DGMC) xác định các giá chuẩn riêng cho than nhiệt, luyện kim và phẩm cấp thấp trên cơ sở hàng tháng. Giá chuẩn đối với than nhiệt được xác định bằng cách sử dụng công thức liên quan đến giá than trung bình dựa trên các chỉ số thị trường trong nước và quốc tế. Chính phủ xác định giá than Tham chiếu (HBA) bằng cách lấy trung bình giá trị nhiệt lượng của than trong bốn chỉ số giá than, cụ thể là:

+Chỉ số than Newcastle (NEX);

+Chỉ số than toàn cầu (GC);

+Chỉ số Platts;

+Chỉ số than Indonesia (ICI).

Hai chỉ số đầu đại diện cho giá quốc tế, hai chỉ số cuối đại diện cho giá than trong nước. Giá chuẩn được xác định cho loại than có nhiệt trị 6.322 $\mathrm{kcal} / \mathrm{kg}$ trên cơ sở nhận được (ARB), độ ẩm ở mức 8\% (ARB), hàm lượng lưu huỳnh ở mức $0,8 \%$ (ARB) và độ tro ở mức 15\% (ARB).

HBA $=25 \%$ ICI- $1+25 \%$ Platts- $1+25 \%$ NEX + $25 \%$ GC

Sau khi xác định HBA, giá than chuẩn (HPB) được tính theo công thức định giá rõ ràng. Theo đó, giá tính toán sẽ áp dụng mức phạt đối với hàm lượng lưu huỳnh cao (phát thải), độ ẩm (tổn thất nhiệt/ vận chuyển hàng hóa) và độ tro. Có 8 loại giá chuẩn, đại diện cho chất lượng than, dao động từ $4.200 \div 7.000 \mathrm{kcal} / \mathrm{kg}$ tính theo tổng cơ sở nhận được (GAR). Đối với than không phải là tám loại HPB, giá được xác định theo phương pháp nội suy. 
Để tránh mọi tranh chấp, việc chuyển đổi giá trị nhiệt lượng than từ dạng cơ sở khô (ADB) sang GAR được thực hiện bằng cách sử dụng phương trình sau:

$$
K_{C A R}=K_{A D B} x \frac{(100-T M)}{(100-M)}
$$

Trong đó: GAR

$\mathrm{K}_{\mathrm{GAR}}$ : Giá trị nhiệt lượng than trong điều kiện $\mathrm{K}_{\mathrm{ADB}}$ : Giá trị nhiệt lượng than trong điều kiện $\mathrm{ADB}$;

TM: Tổng độ ẩm;

M: Độ ẩm.

\subsection{Liên bang Nga}

Việc định giá than ở Nga được thực hiện ở hai cấp độ khác nhau: cho thị trường trong nước và thị trường xuất khẩu. Giá than tại thị trường nội địa được kiểm soát bởi hệ thống phân loại của Nga, thường không tính đến độ tro và lưu huỳnh. Với than xuất khẩu theo Hiệp định than tiêu chuẩn châu Âu (SECA), giá than về cơ bản được đưa ra tùy từng trường hợp cụ thể. Vấn đề quan trọng nhất đối với than nhiệt của Nga là liệu than của Nga có đáp ứng các yêu cầu chất lượng của SECA và do đó có thể được xuất khẩu sang Tây Âu và Châu Á hay không. Thực tế, than nhiệt chất lượng cao là một mặt hàng toàn cầu với các hợp đồng được tiêu chuẩn hóa và giá cả thị trường minh bạch (Plakitkin Yu, 2015).

Các tính chất sau đây ảnh hưởng đáng kể đến giá than nhiệt của Nga:

- Giá trị năng lượng (thường được đo trên cơ sở không tính đến tro) là yếu tố cốt lõi ảnh hưởng đến giá cả. Nó có thể đạt tới $7.000 \mathrm{kcal} / \mathrm{kg}$ đối với than chất lượng cao trong khi than nhiệt cứng thông thường là khoảng $3.500 \div 6.500 \mathrm{kcal} / \mathrm{kg}$. Theo SECA, than nhiệt cao cấp có tiêu chuẩn nhiệt trị phải trên $5.800 \mathrm{kcal} / \mathrm{kg}$.

- Độ tro là một thông số có ảnh hưởng đáng kể đến giá than nhiệt. SECA quy định rằng độ tro phải dưới $10 \%$.

- Hàm lượng lưu huỳnh có thể làm giảm giá than đáng kể. SECA yêu cầu lưu huỳnh dưới $1 \%$.

ở Nga, do độẩm than quá mức dẫn đến khó vận chuyển trong mùa đông, bên cạnh sự suy giảm hiệu suất nhiệt của nhà máy điện, độ ẩm cũng có thể ảnh hưởng đến giá than.

\section{4. Úc}

Thị trường than Úc là điển hình của thị trường than phát triển với sự ra đời, phát triển của sàn giao dịch điện tử đối với than. Nhờ đó, các hình thức giá than theo đúng nghĩa cơ chế thị trường được hình thành: giá giao ngay, các sản phẩm tương lai, phái sinh.

a) Giá than giao ngay

Giá than giao ngay được định nghĩa không chặt chẽ trong giao dịch than quốc tế. Giá giao ngay có thể là giá giao dịch của một lô hàng, hoặc một phần của lô hàng, hoặc nhiều lô hàng. Một số giá giao ngay được sử dụng bởi các nhà cung cấp hoặc người mua nhỏ do họ không có vị thế để xây dựng mối quan hệ lâu dài, trong khi các hợp đồng giao ngay khác dựa trên mối quan hệ lâu dài giữa người bán và người mua. Việc sử dụng hợp đồng giao ngay đang tăng lên vì người mua, những người dưới áp lực giảm chi phí, cần linh hoạt về nguồn cung để phù hợp với sự không chắc chắn về nhu cầu. Đó cũng là do gia tăng số lượng nhà cung cấp và người mua mới trong thương mại than quốc tế, do nhu cầu than nhiệt từ các nhà máy điện ở các nước đang phát triển cũng như các nước phát triển.

Hiện nay, có một số giá giao ngay phổ biến được xây dựng theo thông số kỹ thuật tiêu chuẩn tại các địa điểm khác nhau. Giá giao ngay theo điều kiện FOB tại Newcastle, Australia (cơ sở cho các chỉ số Newcastle) cho xuất khẩu than nhiệt của Úc là một trong các giá giao ngay đó. Các công ty thông tin, được gọi là cơ quan lập các báo cáo, thực hiện các cuộc khảo sát trên thị trường và xuất bản thường kỳ các thông tin về giá giao ngay. Chúng bao gồm Argus, Dịch vụ thông tin than McCloskey (MCIS), Platts và Báo cáo than Nam Phi (SACR).

b) Thị trường tương lai và phái sinh

Đối với kinh doanh than tại Úc cũng như nhiều thị trường than ở các nước phát triển, thị trường tương lai và các sản phẩm phái sinh đang phát triển nhanh và các sản phẩm này cũng tác độnglên giá than. Trong vài năm qua, giống như nhiều mặt hàng khác, giao dịch than đã trải qua một quá trình chuyển đổi lớn với sự phát triển của giao dịch điện tử và các công cụ tài chính phái sinh. Điều này thể hiện sự trướng thành của thị trường than. Ngoài những người mua (nhà máy điện) và người bán (các công ty khai thác than) mua bán than hiện vật, các ngân hàng và thương nhân tài chính tham gia vào thị trường than tài chính (hay thị trường than giấy). Khối lượng giao dịch tại các thị trường này 
đang tăng lên. Điều này đã thay đổi cách thức than được giao dịch và giá cả. Trong khi tồn tại sự khác biệt giữa các thị trường Đại Tây Dương và Thái Bình Dương, đặc biệt về dòng thương mại hiện vật, thì với các sản phẩm tương lai và phái sinh sự khác biệt giữa hai thị trường đang biến mất nhanh chóng do yếu tố giá cả. Tuy nhiên, thị trường tương lai than vẫn chưa đạt đến giai đoạn tương tự như thị trường tương lai dầu. Hiện tại các hợp đồng than tương lai được thanh toán bằng tiền mặt dựa trên các chỉ số giá than được công bố.

Thị trường hoán đổi OTC phát triển mạnh từ cuối những năm 1990, trước khi thị trường tương lai ra đời. Hoán đổi là một sản phẩm phái sinh linh hoạt để phòng ngừa rủi ro giá cả. Ví dụ: Nhà sản xuất than hoặc người tiêu dùng cuối có thể trao đổi giá của một mã than cụ thể với giá cố định hoặc giá được liên kết với giá tham chiếu hoặc liên kết với chỉ số tổng hợp trong một khoảng thời gian bằng cách tham gia vào một thỏa thuận hoán đổi với một tổ chức tài chính. Là một sản phẩm phái sinh OTC, các điều kiện và thông số kỹ thuật của một giao dịch hoán đổi có thể được điều chỉnh phù hợp thông qua đàm phán giữa hai bên (Paul Baruya, 2015), (Rachit Tiwari, 2015).

Năm 2001, Global Coal được thành lập bởi các nhà sản xuất than (Anglo American, BHP Billiton, Glencore và Rio Tinto), các người dùng cuối (ENEL, EON và J-Power) và các đối tác khác. Đây là một nền tảng điện tử để giao dịch cả than hiện vật và các sản phẩm tài chính giữa các thành viên. Global Coal có trụ sở tại London dưới sự giám sát của Cơ quan Dịch vụ Tài chính Vương quốc Anh (FSA). Global Coal công bố chỉ số giá Newcastle13. Được giới thiệu vào năm 2002, chỉ số Newcastle dựa trên giá than nồi hơi FOB tại Sàn giao dịch Newcastle ở Úc, nhằm mục đích thiết lập chính sàn này làm chuẩn mực cho thị trường than nhiệt châu Á - Thái Bình Dương. Một thị trường hoán đổi OTC đã được hình thành xung quanh sàn này trong những năm gần đây.

\subsection{Nam Phi}

Trong lịch sử, ngành than đã phục vụ ba thị trường chính. Phần lớn than sạch (thương phẩm) được xuất khẩu. Chất lượng điển hình của than sạch này có độ tro $\leq 12,5 \%$ và giá trị năng lượng $6.000 \mathrm{kcal} / \mathrm{kg}$ trên cơ sở nhiệt trị ròng thu được (NAR). Một phần nhỏ than chất lượng tương tự, nhưng có kích cõ̃ gần giống với các loại hạt lạc, hạt đậu và đậu xanh truyền thống, được bán trên thị trường nội địa cho nhiều hộ tiêu thụ công nghiệp và hộ tiêu thụ khác. Thành phần thứ ba trong các sản phẩm có thể bán được được gọi là sản phẩm trung gian, có nhiệt trị dao động từ 4.300 đến $5.500 \mathrm{kcal} / \mathrm{kg}$ và được bán cho Công ty độc quyền nhà nước Eskom. Với xu hướng gần đây là tăng tỷ trọng khai thác và làm sạch than chất lượng kém, tỷ lệ tương đối của ba thị trường đang trải qua một sự thay đổi mà không có sự thay đổi về thông số kỹ thuật chất lượng cho cả ba thị trường. Mối quan hệ giữa các thị trường và giá cả của chúng được liên kết chặt chẽ trong những năm gần đây. Mặc dù than cho Eskom và các sản phẩm xuất khẩu có thông số kỹ thuật của sản phẩm hoàn toàn khác nhau, nhiều mỏ sản xuất cả hai sản phẩm này và giá cả thường được tính trên cơ sở chia sẻ chi phí. Bên cạnh giá trị năng lượng, độ tro và chất bốc, chỉ số mài mòn đóng vai trò quan trọng trong việc xác định giá than. Chỉ số mài mòn cao hơn, tuổi thọ của thiết bị tiếp xúc với than sẽ ngắn hơn. Trong số các thông số chất lượng khác, cỡ hạt của than, độ ẩm và hàm lượng lưu huỳnh được giới hạn ở một số giá trị bắt buộc nhất định (World Bank Energy Department, 1985).

Các hệ thống định giá than nhiệt được áp dụng ở các quốc gia khác nhau được tóm tắt trong Bảng 1 (Nguyễn Công Tân, 2020).

\section{Bài học kinh nghiệm rút ra cho Tập đoàn TKV}

Qua nghiên cứu cơ chế xác định giá than của một số quốc gia trên thế giới có thể rút ra một số bài học kinh nghiệm cho việc định giá than đối với Tập đoàn TKV như sau:

-Thứ nhất, cho dù là thị trường trong nước hay thương mại quốc tế, để tiêu chuẩn hoá các thông số chất lượng than trong thực tế, tiêu chuẩn quan trọng nhất đối với than là giá trị năng lượng (hay gọi là nhiệt trị), đây là giá trị thương mại cơ bản của than. Giá cuối cùng của than cũng được xác định bởi các tính chất khác có thể ảnh hưởng đến việc sử dụng thương mại của than, các vấn đề về thị trường và điều kiện môi trường.

-Thứ hai, ngoài việc phụ thuộc vào chất lượng và các vấn đề về môi trường, giá cả trong thương mại than quốc tế cũng phải tuân theo quy luật cung cầu. Giá than cũng được kết nối với những biến động về giá của các loại nhiên liệu thay thế, như khí đốt thiên nhiên hay dầu, ví dụ điển hình là 
Bảng 1. Cơ chế định giá than tại thị trưòng nội địa tại một số nước khai thác than và tiêu thụ than.

\begin{tabular}{|c|c|c|}
\hline Nước & $\begin{array}{l}\text { Cơ chế hình thành } \\
\text { giá than }\end{array}$ & Các biện pháp điều tiết giá than gián tiếp của chính phủ \\
\hline $\begin{array}{l}\text { Trung } \\
\text { Quốc }\end{array}$ & $\begin{array}{l}\text { Về cơ bản, theo thị } \\
\text { trường, đối với than } \\
\text { cung cấp cho một số } \\
\text { ngành giá được quản } \\
\text { lý bởi chính phủ. }\end{array}$ & $\begin{array}{l}\text { Giá than nhiệt được điều tiết một phần. Từ tháng 9/2013, thuế } \\
\text { đã được áp dụng đối với than nhập khẩu. }\end{array}$ \\
\hline Ấn Độ & $\begin{array}{l}\text { Giá than gián tiếp } \\
\text { được quản lý bởi } \\
\text { chính phủ. }\end{array}$ & Giá được xác định bởi công ty nhà nước "Coal India". \\
\hline $\begin{array}{l}\text { Nhật Bản, } \\
\text { Hàn Quốc }\end{array}$ & Thị trường & $\begin{array}{l}\text { Giá được xác định bởi các chỉ số giá thế giới, than được mua } \\
\text { trên cơ sở hợp đồng dài hạn. }\end{array}$ \\
\hline Úc & Thị trường & $\begin{array}{l}\text { Từ tháng 3/ 2012, thuế lợi nhuận đối với các công ty khai thác } \\
\text { quặng và than đã được ấp dụng ở mức 30\%. }\end{array}$ \\
\hline Mỹ & Thị trường & $\begin{array}{l}\text { Một yếu tố quan trọng kìm hãm sự tăng giá ở Mỹ là thuế lợi } \\
\text { nhuận lũy tiến. }\end{array}$ \\
\hline Indonexia & Thị trường & $\begin{array}{l}\text { Giá chuẩn của than được thiết lập vào năm } 2010 \text { để làm căn cứ } \\
\text { tính thuế tài nguyên và thuế xuất khẩu. Mục đích của quy định } \\
\text { này nhằm ngăn chặn việc lạm dụng chuyến giá giữa các nhà cung } \\
\text { cấp và các công ty nước ngoài. Giá chuẩn được xác định hàng } \\
\text { tháng bởi Tổng cục Khoáng sản và Than (DGMC) và được tính } \\
\text { theo công thức dựa trên các chỉ số thị trường trong nước và } \\
\text { quốc tế (đã nêu ở trên). } \\
\text { Thuế tài nguyên theo Luật Khai thác mỏ năm } 2009 \text { được quy } \\
\text { định đối với than có nhiệt trị dưới } 5.100 \mathrm{kcal} / \mathrm{kg} \text { có thuế suất là } \\
3 \% \text {, than có nhiệt trị từ } 5.100 \text { đến } 6.100 \mathrm{kcal} / \mathrm{kg} \text { có thuế suất là } \\
5 \% \text {, than có nhiệt trị trên } 6.100 \mathrm{kcal} / \mathrm{kg} \text { có thuế suất là } 7 \% \text {. } \\
\text { (trước đây thuết tài nguyên là } 13,5 \% \text { hoặc } 13 \% \text { ). }\end{array}$ \\
\hline Đức & $\begin{array}{l}\text { Về cơ bản, theo thị } \\
\text { trường; trong một số } \\
\text { trường hợp, giá than } \\
\text { được chính phủ điều } \\
\text { tiết }\end{array}$ & $\begin{array}{l}\text { Giá than nội địa cao hơn giá than nhập khẩu, chênh lệch giá được } \\
\text { bù từ một quỹ được hình thành bằng nguồn giá điện tăng thêm } \\
10 \% \text {. }\end{array}$ \\
\hline Ba Lan & $\begin{array}{l}\text { Trước năm } 2011 \text { giá } \\
\text { than được chính phủ } \\
\text { xác định; sau năm } \\
2011 \text { - theo thị trường }\end{array}$ & $\begin{array}{l}\text { Từ } 1999 \text { đến } 2011 \text { Ba Lan đã chi hỗ trợ cho ngành công nghiệp } \\
\text { than } 7 \text { tỷ đô la Mỹ, sau đó ngừng hố trợ. }\end{array}$ \\
\hline Anh & $\begin{array}{l}\text { Chính phủ điều tiết } \\
\text { một phần }\end{array}$ & $\begin{array}{l}\text { Giá than nội địa cao hơn giá than nhập khẩu, chênh lệch giá được } \\
\text { bù từ một quỹ được hình thành bằng nguồn giá điện tăng thêm } \\
10 \% \text {. }\end{array}$ \\
\hline Đan Mạch & $\begin{array}{l}\text { Thị trường, chính } \\
\text { phủ giới hạn theo chỉ } \\
\text { số giá thế giới }\end{array}$ & $\begin{array}{l}\text { Giá than phụ thuộc vào giá than thế giới và chi phí vận chuyển } \\
\text { than, bằng một nửa giá CIF cho than. }\end{array}$ \\
\hline Thụy Điể & $\begin{array}{l}\text { Thị trường, chính } \\
\text { phủ tác động một } \\
\text { phần }\end{array}$ & $\begin{array}{l}\text { Nhiều lợi ích được cung cấp dưới hình thức miễn và giảm thuế } \\
\text { suất đối với tiêu thụ năng lượng và khí thải CO2. }\end{array}$ \\
\hline $\begin{array}{l}\text { Thổ Nhĩ } \\
\text { Kỳ }\end{array}$ & $\begin{array}{l}\text { Thị trường, chính } \\
\text { phủ tác động một } \\
\text { phân }\end{array}$ & $\begin{array}{l}\text { Than được mua cho các nhà máy luyện kim chỉ trên cơ sở đấu } \\
\text { thầu để đảm bảo sự minh bạch. }\end{array}$ \\
\hline
\end{tabular}


tăng nào của giá dầu cũng gây ra sự tăng giá than bất kể giá than chuẩn hoặc giá than tham chiếu.

-Thứ ba, cho dù đều áp dụng cơ chế thị trường hoặc hướng tới cơ chế thị trường trong việc định giá than nhưng cách thực hiện ở các nước khác nhau cũng khác nhau tuỳ thuộc vào mức độ phát triển thị trường ở mỗi nước. Úc là nước điển hình có thị trường than phát triển cao với sàn giao dịch điện tử Newcastle. Tại Úc, ngoài các hình thức giá thoả thuận theo truyền thống trực tiếp giữa người bán và người mua, đã hình thành giá giao ngay, các sản phẩm giá tương lai, phái sinh (giao dịch giấy/tài chính đối với than). Điều cần nhấn mạnh là các giao dịch truyền thống ngày càng lấy giá giao ngay làm cơ sở để thanh toán giữa các bên. Indonexia tuy chưa có sàn giao dịch điện tử nhưng cũng lấy chỉ số giá của các sàn giao dịch nước ngoài làm cơ sở xác định giá tham chiếu. Trung Quốc tuy đang trong quá trình hoàn thiện cơ chế thị trường đối với than nhưng vẫn còn sự can thiệp của Nhà nước trong việc gắn giá than với giá điện, các ràng buộc về xuất nhập khẩu (gián tiếp tác động đến giá than). Thị trường than Nam Phi vận hành tương tự thị trường than Úc nhưng điểm rất đáng lưu ý là sự phân biệt thị trường than xuất khẩu, thị trường than cho điện, và thị trường than cho các hộ tiêu thụ khác.

\section{Kết luận}

Như vậy, có thể thấy cơ chế định giá than là một vấn đề phức tạp và ở nhiều quốc gia cơ chế định giá than đã được vận hành theo cơ chế thị trường song vẫn có sự quản lý của Nhà nước. Đối với Việt Nam, cơ chế quản lý, điều hành giá bán than phù hợp với ngành than Việt Nam sẽ là cơ sở định hướng cho việc điều hành giá than của Tập đoàn TKV cũng như sự giám sát của Nhà nước về giá bán than, qua đó góp phần đảm bảo lợi ích giữa các doanh nghiệp sản xuất kinh doanh than cũng như các hộ tiêu thụ than và đảm bảo an ninh năng lượng quốc gia.

\section{Những đóng góp của tác giả}

Tác giả Nguyễn Công Tân hình thành ý tưởng, triển khai các nội dung và chịu trách nhiệm chính về nội dung bài báo; tác giả Lưu Thị Thu Hà cùng triển khai các nội dung, đọc và hoàn thiện bài báo; tác giả Đồng Thị Bích thu thập, tổng hợp thông tin và đọc bài báo.

\section{Tài liệu tham khảo}

Nguyễn Công Tân, (2020). Nghiên cứu xây dựng khung biểu giá than và đề xuất cơ chế quản lý, điều hành giá than tại Việt Nam", Báo cáo tổng kết đề tài cấp ngành mã số: KC.06.Đ34-19/1620, Công ty cổ phần tư vấn Đầu tư Mỏ và Công nghiêp - Vinacomin.

Paul Baruya, (2015). Coal contracts and long-term supplies, CCC/ 258, IEA Clean Coal Centre, 76 pages.

Plakitkin Yu.A.,(2015). Hình thành giá than: thông lệ trong nước và thế giới, ISSN 0041-5790 • THAN số 1-2015/ 1066.

Rachit Tiwari, (2015). A Discussion in Noncoking Coal Pricing Systems Adopted in Different Countries, Indian Institute of Management, Ahmedabad, SAGE Publications, VIKALPA The Journal for Decision Makers 40(1) 62-73.

ZhongXiang Zhang and Ma Yinchu, (2018). Energy Price Reform in China, School of Economics and China Academy of Energy, Environmental and Industrial Economics, Tianjin University, 1243 -1244.

World Bank Energy Department, (1985), Domestic Coal Pricing: Suggested Principles and Present Policies in Selected Coountries, 145 189. 